\title{
International perspectives on using OER for online learning
}

\author{
Dabae Lee $^{1} \cdot$ Eunbae Lee $^{2}$ (D) \\ Accepted: 31 October 2020 / Published online: 23 November 2020 \\ (c) Association for Educational Communications and Technology 2020
}

\begin{abstract}
This article examines the work by Hilton (Educ Technol Res Dev 64: 573-590. https:// doi.org/10.1007/s11423-016-9434-9, 2016) entitled, "Open educational resources and college textbook choices: A review of research on efficacy and perceptions" from international perspectives. Hilton (Educ Technol Res Dev 64: 573-590. https://doi.org/10.1007/s1142 3-016-9434-9, 2016) synthesized findings of 16 studies that investigated the academic outcomes of open educational resources (OER) and perceptions of college students and instructors. The academic outcomes were comparable to using traditional textbooks, and perceptions were positive. His work highlights effectiveness of OER in online courses resulting from their technological affordances. The COVID-19 pandemic pushed many institutions around the globe to abruptly shift their instructions digital and make learning more flexible and affordable for those who face medical, financial, and daily life challenges. Hilton's findings (Educ Technol Res Dev 64: 573-590. https://doi.org/10.1007/ s11423-016-9434-9, 2016) provide collective evidence to support the adoption of OER and shed light on how it can be used and what future work is needed internationally. This article examines the international value, implications, and limitations of his work and suggests future directions.
\end{abstract}

Keywords Open educational resources · Online learning · COVID-19 $\cdot$ International perspectives

Hilton (2016) synthesized 16 studies regarding the effects of open educational resources (OER) on academic outcomes and perceptions of college students and instructors. OER is defined as teaching, learning, and research materials that users access, use, adapt, and redistribute at no cost (UNESCO, n.d.). Nine studies were identified that compared OER with traditional textbooks in higher education settings with at least 50 participants. He concluded that academic outcomes were comparable between students who used OER and those who used traditional textbooks. Students and instructors generally perceived OER favorably. During the COVID-19 pandemic, many institutions worldwide had to shift their

Eunbae Lee

elee@catholic.ac.kr

1 Kennesaw State University, Kennesaw, GA, USA

2 The Catholic University of Korea, Dasol Hall \#237 Jibong-ro 43, Wonmi-gu, Bucheon city, Gyeonggi-do 14662, South Korea 
instructions digital and make learning flexible and affordable for those who face medical, financial, and daily life challenges. This study provides collective evidence to support the adoption of OER and sheds light on benefits of OER, how it can be used in online courses, and what future work is needed internationally.

\section{International impact and value of OER}

The potentials of OER in education is globally recognized (Educause, 2020; European Commission, 2013). Countries in Europe, North and South Americas, and Asia are actively developing OER materials and finding ways to encourage educators to adopt OER, and more than 1,000 international repositories of OER exist (Santos-Hermosa, Ferran-Ferrer, \& Abadal, 2017).

The obvious benefit of OER is cost-saving by students, which Hilton (2016) recognized as the primary reason for faculty's adoption and students' positive perceptions. According to On Campus Research (2018), U.S. students spent about \$484 on course materials annually. About $85 \%$ of college students in North America delayed or avoided purchasing course materials, and approximately $90 \%$ reported that cost is a critical reason (Wakefiled Research, 2018). In a different national survey, 55\% of the U.S. faculty selected cost as the primary reason for their students not having access to course materials (Seaman \& Seaman, 2019). The cost-saving benefit will be perceived more critically due to the economic crisis faced by many countries. World Bank (2020a) forecasts the global economy will shrink by $5.2 \%$, which represents the deepest recession since the World War II. It estimates at least 70 million additional people worldwide are pushed into extreme poverty due to COVID-19 (Mahler, Lankner, Aguilar, \& Wu, 2020).

It is notable that students were equally or more successful without using costly textbooks in online or blended courses (Hilton, 2016). The compatibility of OER with online environments and its instant access make OER even more attractive during the pandemic. World Bank (2020b) reports that institutions in about 160 countries faced building closures due to the pandemic. According to a recent survey, $90 \%$ of U.S. institutions abruptly transitioned some or all of their classes online (Bay View Analytics, 2020). In the survey, $61 \%$ of institutions and $52 \%$ of faculty selected a greater access to digital materials as the most helpful assistance needed (Bay View Analytics, 2020). Interestingly, in another survey, 56\% of the faculty were not aware of OER, 23\% were using OER as supplemental resources, and $14 \%$ used as required course materials (Seaman \& Seaman, 2019). A reason for the gap between the awareness and adoption rates can be faculty's skepticism over the efficacy of OER. Hilton's work (2016) contributes to closing the gap by providing various OER adoption cases, evidence of effectiveness, and faculty and students' positive perceptions.

\section{Implications for online learning}

Because most OER are digital that allow users to use, distribute, and adapt materials, OER can be more easily, efficiently, and effectively integrated into online instructions than traditional textbooks. Three studies examined by Hilton (2016) compared academic outcomes for using OER in online or blended formats to those for using traditional textbook in faceto-face formats. Although these studies bear some methodological threats by comparing 
OER to traditional textbooks in different conditions without eliminating alternative possibilities, the positive learning outcomes from the online formats underscore technological affordances of OER to be highlighted in the pervasive online learning in current and future pandemic crises.

Instructors may utilize OER with other digital tools to create engaging online learning experiences. Many tools support multiple languages to be used internationally. Using annotation tools like Hypothes.is, instructors can highlight and annotate in digital print materials. It allows students to discuss and collaborate around the materials. Using a tool like Edpuzzle, instructors can annotate in videos. Assessments can be easily embedded into OER using tools like Edpuzzle, Spiral, Flipgrid, and Formative. For instance, Formative (goformative.com) allows users to turn instructional resources like PDF worksheets into online assessments to implement synchronously and asynchronously.

\section{Limitations}

The study bears some limitations. First, the findings are limited to the studies conducted in the U.S. and more international evidence is needed. Different cultural, economic, political, and technological factors may affect the efficacy and users' perceptions of OER. Therefore, more studies that examined the use and effects of OER should be conducted in different contexts to facilitate institutional adoptions of OER.

Second, the study is focused on outcomes of using OER and does not provide much guidance about how to facilitate faculty's creation, adoption, and effective use of OER. Mere adoption of OER does not guarantee comparable learning outcomes and favorable perceptions. More specific guidelines of what works and how to effectively integrate OER in specific cultural and learning contexts should be explored (Wiley \& Hilton, 2018).

\section{Future steps}

At the 2019 UNESCO General Conference meeting, member countries unanimously agreed to build capacity to generate and use OER, develop supportive policy nurturing the creation of sustainability models for OER, and facilitate international cooperation (UNESCO, 2019). To do so, universal technological and quality standards for OER and their repositories should be developed and applied. There should be technical requirements for OER repositories that enable (1) users' easy access, adoption, and adaptation of OER for effective and efficient integrations (Santos-Hermosa et al., 2017); (2) users' evaluation of OER in terms of the universal quality standards; and (3) users' interaction and collaboration for continuous improvement of OER. A common set of metadata requirements should be established to allow for easy retrieval including types of OER, grade levels, subject areas, topics, and users' ratings. According to a comprehensive review on OER repositories, users' reviews and collaborative approaches to quality are critical to sustainability (Clements, Pawlowski, \& Manouselis, 2015).

Funding This study is funded by the Catholic University of Korea Research Fund M-2018-B0014-00101. 


\section{Compliance with ethical standards}

Conflict of interest The authors declare that they have no conflict of interest.

Informed consent No human subjects are involved in the present article, and informed consent is not applicable.

\section{References}

Bay View Analytics. (2020). Digital learning purse survey: Immediate priorities. https://www.onlin elearningsurvey.com/covid.html

Clements, K., Pawlowski, J., \& Manouselis, N. (2015). Open educational resources repositories literature review: Towards a comprehensive quality approaches framework. Computers in Human Behavior, 51, 1098-1106. https://doi.org/10.1016/j.chb.2015.03.026.

Educause. (2020). 2020 Educause horizon report: Teaching and learning edition. https://library.educa use.edu/resources/2020/3/2020-educause-horizon-report-teaching-and-learning-edition

European Commission. (2013). Communication from the Commission to the European Parliament. Opening up education: Innovative teaching and learning for all through new technologies and open educational resources. https://eur-lex.europa.eu/legal-content/EN/TXT/PDF/?uri=CELEX\%3A520 13DC0654\&amp;amp\%3Bamp\%3Bfrom $=\mathrm{EN}$

Hilton, J. (2016). Open educational resources and college textbook choices: A review of research on efficacy and perceptions. Educational Technology Research and Development, 64, 573-590. https:// doi.org/10.1007/s11423-016-9434-9.

Mahler, D. G., Lankner, C., Aguilar, R. A. C., \& Wu, H. (2020). Updated estimates of the impact of COVID-19 on global poverty. https://blogs.worldbank.org/opendata/updated-estimates-impac t-covid-19-global-poverty

On Campus Research. (2018). Student Watch: Attitudes and behaviors toward course materials, 201718 Report. https://www.oncampusresearch.org/student-watch

Santos-Hermosa, G., Ferran-Ferrer, N., \& Abadal, E. (2017). Repositories of open educational resources: An assessment of reuse and educational aspects. International Review of Research in Open and Distributed Learning, 18(5), 84-120. https://doi.org/10.19173/irrodl.v18i5.3063.

Seaman, J. E., \& Seaman, J. (2019). Inflection point: Educational resources in U.S. higher education. https://www.onlinelearningsurvey.com/reports/2019inflectionpoint.pdf

UNESCO. (2019). UNESCO recommendation on Open Educational Resources (OER). https://en.unesc o.org/news/unesco-recommendation-open-educational-resources-oer

UNESCO. (n.d.). Open Educational Resources (OER). https://en.unesco.org/themes/building-knowl edge-societies/oer

Wakefiled Research. (2018). VitalSource survey: QuickRead report. https://get.vitalsource.com/hubfs 12018\%20Wakefield/Wakefield\%20Research\%20QuickRead\%20Report\%20for\%20VitalSource.pdf

Wiley, D., \& Hilton, J. L. (2018). Defining OER-enabled pedagogy. International Review of Research in Open and Distributed Learning, 19(4). https://doi.org/10.19173/irrodl.v19i4.3601.

World Bank. (2020a). COVID-19 to plunge global economy into worst recession since World War II. https://www.worldbank.org/en/news/press-release/2020/06/08/covid-19-to-plunge-global-econo my-into-worst-recession-since-world-war-ii

World Bank. (2020b). World Bank Education and COVID-19. https://www.worldbank.org/en/data/inter active/2020/03/24/world-bank-education-and-covid-19

Publisher's Note Springer Nature remains neutral with regard to jurisdictional claims in published maps and institutional affiliations.

Dabae Lee Ph.D., is an assistant professor in the Department of Instructional Technology at Kennesaw State University. She has received several awards, the Young Researcher Award, Emerging Scholar Award, and Outstanding Presentation Awards from the Association of Educational Technology and Communications and the President's Research and Creativity Award from her previous institution. Her research interests 
include personalized learning, roles of technology in personalized learning, student collaboration, online learning design, active learning spaces, and research methods in Instructional Technology.

Eunbae Lee Ph.D., is assistant professor at the Catholic University of Korea. She received her Ph.D. in Learning, Design, and Technology from the University of Georgia. Her research interest centers on studentcentered learning, online learning, creative problem solving, and innovation. 